\title{
Thai Language is a Factor Affecting the Selection of Chinese Travel Companies to Visit in Thailand.
}

\author{
Caizhen Xu, Dr.Chinnaso Visitnitikija \\ Graduate School of Business Administration Kasembundit university, Bangkok
}

\begin{abstract}
The study of behavior and factors affecting the selection of Chinese tour operators for Chinese tourists visiting Thailand. Is a quantitative study (Quantitative Research) Population Studies The instruments used in the study were statistic questionnaire used for data analysis, percentage mean, chi-square test, and regression analysis. The study indicated that 400 respondents. Mostly female Age between 21-30 years old. There are other professions such as agriculture. Monthly income is over 33,500 baht / month. Tourism behavior of Chinese tourists to Thailand. I found most of friends traveling most.

Traveling by the convenience of self-management to find information to travel to Thailand from the acquaintances. Traveling to relax and spend on other types of souvenirs such as Thai food, dried fruits, and most fruits.

Most of them prefer to stay at the hotel, and most of them want to come back again and spend more than 100,000 baht / visit. The marketing mix factors affect the tourist behavior of Chinese tourists. To come to Thailand. According to studies, it has been found that The overall picture is very agreeable in all aspects. Product price aspects of distribution channels. Marketing promotion Person or employee Process And the creation and presentation of physical characteristics.

Suggestions for travel managers should include new attractions at discounted prices. There should be a wide variety of travel agencies, such as self-contact, telephone, e-mail, etc. There should be more books or supplementary knowledge about Thailand or tourist attractions.

Service personnel and guides should have a good understanding of the needs and the needs of each customer. The confidentiality of the customer should be maintained and the customer's recommendation to improve the service. Travel agents should make a variety of package tours.
\end{abstract}

Keyword: factor affecting behavior

\section{Introduction}

Tourism is an important industry for the economic and social development of the country. Because the tourism brings revenue into the country several hundred billion a year. It also has a tendency to become more important in the future. This is because international tourism can earn money in the international currency to help offset the country's deficits due to trade deficits.

Domestic tourism also stimulates investment in the production of goods and services, which helps create jobs, create jobs and distribute income to all levels of the profession. Therefore, it is necessary to pay attention to develop and promote tourism into a tourism industry that can effectively meet the needs of tourists. To attract foreign tourists to come to Thailand and bring income from tourism to the country to).To attract foreign tourists to come to Thailand and bring income from tourism to the country to flourish

The tourism industry is considered to be a large and rapidly growing service industry. The industry is driven by a multitude of business partnerships, including food and beverage, transportation, travel, beauty and health 
and hospitality.Currently, the tourism industry is a global economic industry. Because it can generate huge income for the country, it can also create jobs for the people of the country as well. Since 1997.

The state began to focus on the tourism industry, Thailand has several strengths that can compete with other countries in the regional government is paying attention and policy support to come on tour. Thailand is known as to the purpose and destination of tourists from around the world by providing campaigns such as "Amazing Thailand" to pull off. The foreign tourists and "Visiting a new heart in Thailand sustainability" to encourage tourists to travel in Thailand, so Thailand..

From the past statistics. Thailand has a large number of foreign tourists from all regions of the world. The number of foreign tourists is a market that is very much interested in the market is. Chinese tourist markets, global organizations and agencies in many countries around the world place importance on the People's Republic of China as a potential market for both the manufacturing and service industries.

Since it is the most populous country in the world, it is about 1300 million people, and China is likely to have more purchasing power due to higher incomes. This makes China one of the potential markets as a major global exporter.

Since it is the most populous country in the world, it is about 1300 million people, and China is likely to have more purchasing power due to higher incomes. This makes China one of the potential markets as a major global exporter.

Many countries are urgently urging Chinese tourists to come to their home countries because they are well aware of the buying power market and tastes of Chinese consumption, especially in big cities such as Shanghai, which has grown exponentially in line with economic growth. Population Thailand is the first overseas tourist market of Chinese, Thai culture, Thai food and Thai tourist attraction quite prevalent among Chinese.

From above It can be seen that the number of Chinese tourists traveling to Thailand has a high growth rate. Tourism needs to be adjusted to attract more Chinese tourists as well. There are direct flights from many cities in China to Thailand. The decision to cancel visas for Chinese people to come to. Thailand, Japan, Korea, Taiwan, as well as Russia. It is evident that above the Chinese tourist market is a fast-growing market, with Chinese tourists traveling out of the country increasing every year due to the economic expansion. The country and the Chinese government began to allow more people to leave the country. Thailand is especially geographically close to ethnicity, traditions and culture, so it is easy for travelers in Thailand to visit China. the findings tourist market in Asia.

\section{Purpose of study}

1. To study the factors affecting the selection of Chinese travel agents of Chinese tourists to Thailand.

2. To study the tourist behavior of Chinese tourists in Thailand.

\section{Concept of Framework}

Independent variables

- Sex - Age - Education

Career - Average income /

month
Variable

Travel behavior of Chinese tourists to Thailand.

Marketing mix

1 (Product)2 ( Price ) 3 ( Place ) 4 ( Promotion )5 ( People ) ( Employee )

6(Physical Evidence and Presentation) 7( Process) 


\section{Research Methodology}

The study indicated that 400 respondents. Mostly female Age between 21-30 years old. There are other professions such as agriculture. Monthly income is over 33,500 baht / month. Tourism behavior of Chinese tourists to Thailand. I found most of friends traveling most.

\section{Research Result}

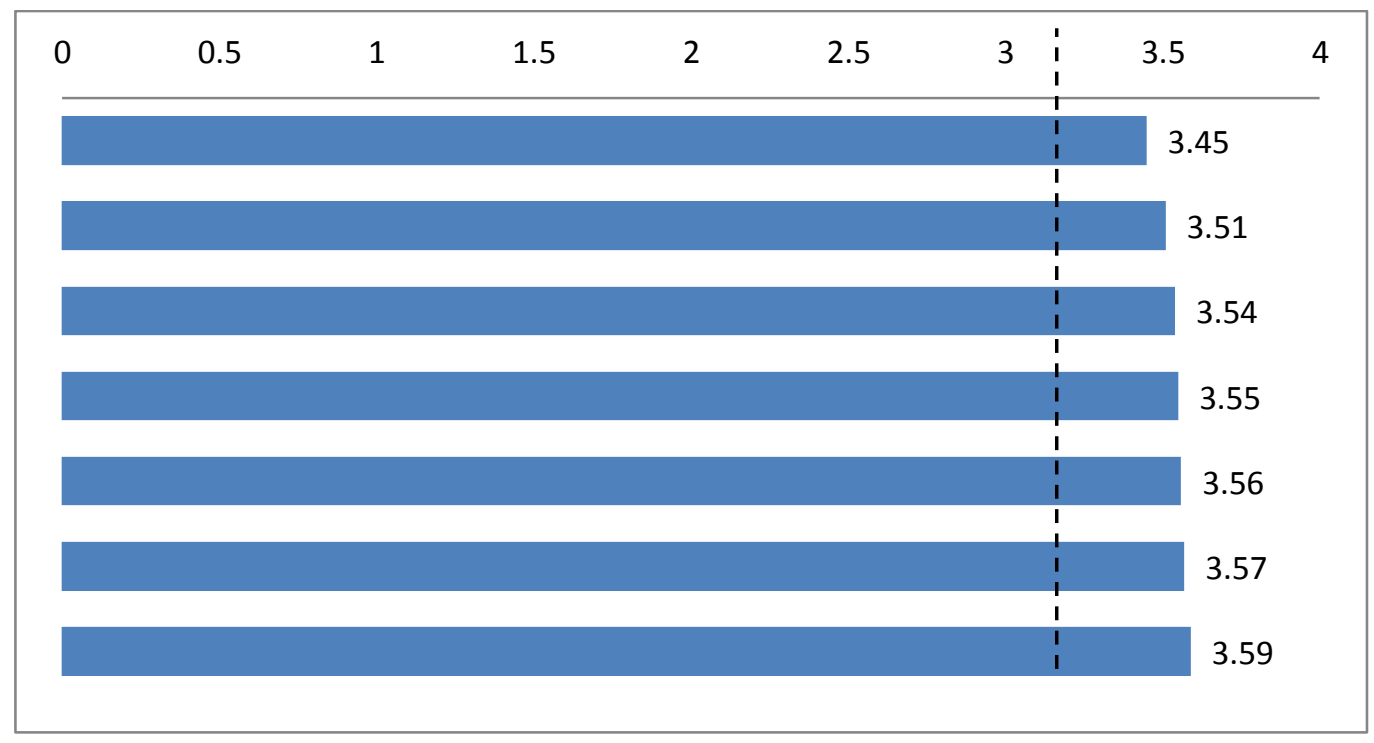

Fig. 1: Show the average number of 7 different aspects of the overall picture.

From Figure 4.23, it was found that the level of opinions on marketing mix factors The overall picture is very high. The samples agreed on the products and distribution channels as much as possible. Mean is 3.65 and 3.59 , followed by price. Mean average of 3.57 processes. The mean is 3.54 and the person or employee. The mean score of 3.51 is the least. It is the creation and presentation of the physical characteristics. The average is 3.45 .

\section{Summery}

The respondents were 400 respondents. Mostly female Age 21-30 years The education level is under the bachelor degree, there are other professions such as agriculture. Monthly income is over 33,500 baht / month. This study is a study of factors affecting the decision of choosing Chinese travel companies to visit Thailand. Therefore, the next study should isolate the study of tourists from other countries in order to improve the results of tourism in the next.

\section{Reference}

[1] Thanin Trairak. (2011). Marketing Factors that have Influences on Customers in Bangkok's Purchasing Decision for Products in Man-U Shop. Independent study. Marketing Major. Faculty of Business Administration. Rajamangala University of Technology Thanyaburi.

[2] Thongchai Santiwong. (1997). Consumer Behavior. Bangkok: Thaiwattanapanich 